\title{
Communication behaviors and patient autonomy in hospital care: A qualitative study
}

\author{
Zackary D. Berger ${ }^{\mathrm{a}, \mathrm{b}, *}$, Emily F. Boss ${ }^{\mathrm{c}}$, Mary Catherine Beach ${ }^{\mathrm{a}, \mathrm{b}}$ \\ a Division of General Internal Medicine, Johns Hopkins School of Medicine, Baltimore, MD, USA \\ ${ }^{\mathrm{b}}$ Berman Institute of Bioethics, Johns Hopkins University, Baltimore, MD, USA \\ ${ }^{\mathrm{c}}$ Department of Otolaryngology, Johns Hopkins School of Medicine, Baltimore, MD, USA
}

\section{A R T I C L E IN F O}

\section{Article history:}

Received 29 August 2016

Received in revised form 1 March 2017

Accepted 3 March 2017

\section{Keywords:}

Autonomy

Hospitals

Doctor-patient communication

Shared decision making

Patients

Hospitalists

\begin{abstract}
A B S T R A C T
Background: Little is known about how hospitalized patients share decisions with physicians.

Methods: We conducted an observational study of patient-doctor communication on an inpatient medicine service among 18 hospitalized patients and 9 physicians. A research assistant (RA) approached newly hospitalized patients and their physicians before morning rounds and obtained consent. The RA audio recorded morning rounds, and then separately interviewed both patient and physician. Coding was done using integrated analysis.

Results: Most patients were white (61\%) and half were female. Most physicians were male (66\%) and of Southeast Asian descent (66\%). All physicians explained the plan of care to the patients; most believed that their patient understood. However, many patients did not. Physicians rarely asked the patient for their opinion. In all those cases, the decision had been made previously by the doctors. No decisions were made with the patient. Patients sometimes disagreed.

Conclusions: Shared decision-making may not be the norm in hospital care. Although physicians do explain treatment plans, many hospitalized patients do not understand enough to share in decisions. When patients do assert their opinion, it can result in conflict.

Practice implications: Some hospitalized patients are interested in discussing treatment. Improving hospital communication can foster patient autonomy.
\end{abstract}

(C) 2017 Elsevier B.V. All rights reserved.
Respect for autonomy is universally recognized as a foundational principle in bioethics [1]. Respecting patient autonomy is classically discussed in terms of honesty from clinicians (e.g. about prognosis in the face of serious illness) and informed consent, which is legally required for invasive medical procedures. Respect for autonomy also provides the theoretical and psychological foundation for shared decision-making and many forms of behavior change counseling, such as motivational interviewing. In the ambulatory setting, patient understanding and involvement in treatment plans (shared decision making) is seen as essential because these plans tend to be carried out by the patient, whereas in the inpatient setting, they tend to be carried out on the patient [2,3].

Hospitalized patients are sicker, and clinicians may assume (perhaps correctly) that patients will give universal agreement to their treatment recommendations. One observational study found

\footnotetext{
* Corresponding author at: Johns Hopkins Outpatient Center, 601 N Caroline St., Suite 7143, Baltimore, MD, 21287, USA

E-mail address: zberger1@jhmi.edu (Z.D. Berger).
}

that "to a large extent" medical decisions in the inpatient setting were made by doctors before being discussed with the patients [4]. If many hospitalized patients prefer physicians to make decisions, then the minimum standard we might expect for physicians to respect patient autonomy would be for patients to fully understand their diagnosis and treatment plan. Yet studies have consistently shown that patients do not understand the majority of what has happened to them in the hospital, and that physicians overestimate patient understanding [5-8].

There are very few studies directly observing encounters between physicians and hospitalized patients, especially when compared to the large body of research directly observing ambulatory encounters. Farnan et al. provided a review of communicative domains relevant to quality care in the inpatient domain provided by hospitalists, including communicating and promoting partnership with patients; ensuring safe and effective transitions and handoffs of care; and using systems to encourage continuity of care [9]. The extant empirical literature falls into several broad categories. In terms of emotional rapport, one study found that patients perceive physicians to have spent more time with them if the doctor sits rather than stands in their hospital 
room [10], and another study found that physicians tend to avoid responding to patients' expression of negative emotion during dialogue in the hospital, especially if that communication involved an explicit concern [11]. In terms of communication content, one study found that most communication by physicians to patients on hospital ward rounds was focused on the transfer of medical information; patients, on the other hand, communicated about medical information less often than question-asking and checking information already received [12]. Finally, a limited literature addresses decision making in the hospital. One study by Oftstad et al. based on transcripts of ambulatory, emergency room, and hospital dialogues found that decisions in the healthcare context were made over a span of time exceeding the clinician-patient dialogue itself [13].

In terms of hospitalized patients' understanding of their diagnosis and treatment plans, several studies employed survey methodology to demonstrate that patients do not understand as much as physicians think they do. Calkins et al. surveyed physicians and patients post-discharge and found that physicians overestimated their patients' understanding of postdischarge treatment plan [14]. Similar findings obtain for understanding of reason for admission [5]; in particular, there are several studies examining communication of the risk and diagnosis of acute coronary syndrome, showing lack of concordance in understanding between clinician and patient [15]. With a relative dearth of studies observing communication between hospitalized patients and physicians, it is not entirely known how these misunderstandings occur.

Thus, the literature lacks analysis of communication in the inpatient hospital setting, and in particular the ways in which decision making and communicative practices interact. Our goal in this study was to evaluate communication between physicians and inpatients, examine the extent to which hospitalized patients exercise their autonomy during communication with physicians, demonstrate ways in which physicians facilitate patient autonomy, and identify opportunities for engaging patients in their own hospital care.

\section{Methods}

\subsection{Study design, subjects and setting}

We conducted an observational study of patient-doctor communication on an inpatient medicine service. Study subjects were hospitalized patients and hospitalist physicians on a geographically-defined hospitalist service at a single, urban academic medical center. Members of the treatment team included hospitalist (attending) physicians and nurses as well as support staff. All hospitalist physicians who were on the inpatient service during data collection were eligible for the study. Patients were eligible for the study if they were physically located on the hospitalist service during data collection (i.e., not in another part of the hospital for treatment), English-speaking, and able to understand the study and give informed consent. All study procedures were approved by the Johns Hopkins Institutional Review Board (IRB).

\subsection{Data collection methods}

Patients were recruited from December 2011 to May 2012. At the beginning of the day, a research assistant had access to a list of newly admitted patients to the service. Before the patients were seen by the hospitalist physician, the research assistant assessed the patients' eligibility, entered patient rooms and informed them about the study using an IRB-approved script, and assessed their understanding of and interest in the study. If patients expressed interest, they provided consent to participate.

Thereafter, the research assistant approached the hospitalist physician taking care of the patient who had consented to participate in the study. If a hospitalist declined to participate in the study, neither the patient nor the physician were recorded or interviewed. If a hospitalist agreed to participate, the research assistant recorded the rounds on that patient with a digital audio recorder. Any third parties present in the room at the time of rounds gave their oral informed consent. On each subsequent day of the patient's hospitalization, the RA recorded subsequent conversations. The RA only recorded one 'main' patient-physician encounter daily for each patient.

After rounds, the RA conducted brief semi-structured interviews once daily separately with physicians and patients who had agreed to participate in the study. The content of the interviews were based on a priori hypotheses about physician and patient knowledge of reasons for admission and criteria for discharge; communication between physician and patient; and engagement of the patient in their own care. Interview questionnaires are found in the Appendix.

\subsection{Coding methodology}

Two reviewers (ZB and MCB) each read all transcripts (patientphysician dialogues, patient interviews, and physician interviews) in their entirety, focusing on behaviors which would reflect or affect patients' exercise of autonomy in the hospital. Our approach owes much to the integrative qualitative communication analysis presented by Salmon et al. [16], In particular, letting methodological purity be subordinate to data; adopting a multidisciplinary approach with features of conversational analysis, discourse analysis, and interactional analysis; and their model of two interlinked strands. In our case, one strand comprised the withincase analysis and one the between-case, integrative analysis of the entire set of transcripts.

\subsubsection{Within-case strand}

The units of analysis were the inpatient rounds and associated interviews for each case. We began by using the doctor-patient dialogue as the basis for understanding their interaction, with interviews of physician and patient as checks and reflections on that interaction. Analysis was iterative between the dialogue and interviews, using each as a point of comparison for interpreting the other. The reviewers used the entirety of each case to understand the behaviors displayed by patient and physician in the context of the particular relationship, hospitalization, and case disposition. We paid particular attention to how physicians facilitated (or not) and patients exercised their autonomy (or not), in their understanding of their situation and decision-making.

\subsubsection{Between-case, integrative analysis}

Thereafter, the reviewers compared the behaviors noted in each within-case strand between individual cases, noting patterns in patient behavior, physician behavior, and their interaction, and organizing such interactions into representative types.

\section{Results}

\subsection{Patient and physician characteristics}

We audio-recorded 22 patient-doctor dialogues, representing 18 separate patient hospitalizations. Most hospitalizations $(n=18)$ lasted no more than one day but 4 patients stayed two days and were thus recorded twice. As well, we recorded 22 corresponding interviews with 9 hospitalists and 22 interviews with the 18 
Table 1

Patient and physician characteristics.

\begin{tabular}{|c|c|}
\hline \multicolumn{2}{|l|}{ Patients $(\mathrm{N}=18)$} \\
\hline Age & Mean 57 (range 21-81) \\
\hline Female & $\mathrm{N}=9$ \\
\hline \multicolumn{2}{|l|}{ Race } \\
\hline African American & $N=6$ \\
\hline White & $\mathrm{N}=11$ \\
\hline Refused & $\mathrm{N}=1$ \\
\hline \multicolumn{2}{|l|}{ Previously Admitted to This Hospital } \\
\hline Yes & $\mathrm{N}=9$ (mean previous admissions: 1.4$)$ \\
\hline No & $\mathrm{N}=9$ \\
\hline \multicolumn{2}{|l|}{ Reason for Admission } \\
\hline Gastrointestinal (e.g. chronic pancreatitis, gallstones, etc.) & $\mathrm{N}=8$ \\
\hline Cardiac (e.g. chest pain, atrial fibrillation) & $\mathrm{N}=4$ \\
\hline Neurologic & $\mathrm{N}=2$ \\
\hline Possible cancer & $\mathrm{N}=2$ \\
\hline Other (Fall and COPD) & $\mathrm{N}=2$ \\
\hline \multicolumn{2}{|l|}{ Physicians $(\mathrm{N}=9)$} \\
\hline Age & Mean 37 (range 32-45) \\
\hline Female & $\mathrm{N}=3$ \\
\hline \multicolumn{2}{|l|}{ Race } \\
\hline African American & $\mathrm{N}=1$ \\
\hline White & $\mathrm{N}=2$ \\
\hline Southeast Asian & $\mathrm{N}=6$ \\
\hline Number of Years in Practice & Mean 7 (range 1-16) \\
\hline
\end{tabular}

Table 2

Summary of physician and patient behaviors that facilitate or undermine patient understanding and involvement.

\begin{tabular}{|c|c|c|}
\hline & Physician Behaviors/Factors & Patient Behaviors/Factors \\
\hline Facilitate Understanding & $\begin{array}{l}\text { Communication Behaviors } \\
\text { Explains reasoning } \\
\text { Signals that s/he will explain reasoning } \\
\text { - Summarizes plan } \\
\text { - Ask if patient has questions } \\
\text { - Assesses patient understanding } \\
\text { - Contextual Factors } \\
\text { Aware patient doesn't understand }\end{array}$ & $\begin{array}{l}\text { Communication Behaviors } \\
\text { Asks questions } \\
\text { - Repeats plan to clarify } \\
\text { - Asks for clarification } \\
\text { - Is informed } \\
\text { - Contextual Factors } \\
\text { - Wants to be informed }\end{array}$ \\
\hline Undermine Understanding & $\begin{array}{l}\text { Communication Behaviors } \\
\text { Gives too little information } \\
\text { - Misses verbal clues to patient misunderstanding } \\
\frac{\text { Contextual Factors }}{\text {. Not aware that patient doesn't understand }}\end{array}$ & $\frac{\text { Communication Behaviors }}{\text {. Forgets to ask questions or express concerns }}$ \\
\hline Facilitate Patient Involvement & $\frac{\text { Communication Behaviors }}{\text { Asks patient opinion }}$ & $\frac{\text { Communication Behaviors }}{\text { Questions plan and states own opinion }}$ \\
\hline Undermine Patient Involvement & $\begin{array}{l}\frac{\text { Communication Behaviors }}{\text { Directive (struggle) }} \\
\text { Changes plan without telling patient (struggle) }\end{array}$ & $\begin{array}{l}\frac{\text { Contextual Factors }}{\text {. Not interested in making decisions }} \\
\text { - Angry and refusing to engage }\end{array}$ \\
\hline
\end{tabular}

patients. The total recording time of all dialogues and interviews was $558 \mathrm{~min}$. Characteristics of the patients and physicians are found in Table 1 . Most patients were white (61\%) and half were female. Most physicians were male (67\%) and of Southeast Asian descent (67\%).

\subsection{Patient understanding of illness and treatment plan}

A summary of physician and patient behaviors that facilitate or undermine patient understanding and involvement is found in Table 2, and described in detail below. The figure shows how physician and patient behaviors as described in the dialogues and interviews might illustrate ideal communication to enable patient understanding and involvement (Fig. 1).

\subsubsection{Physician factors related to patient understanding}

2.2.1.1. Physician communication behaviors that facilitate patient understanding. We identified five physician communication behaviors that explicitly facilitated the patient's understanding of their illness and the treatment plan: (1) explaining medical reasoning around diagnostic possibilities and plans, (2) signaling that s/he will explain reasoning, (3) offering patients the opportunity to ask questions, (4) summarizing the plan, and (5) assessing patient understanding. Examples of each are found in Table 3. Of these, assessing patient understanding was by far the least common. However when it was done, it yielded meaningful information about the patient's state of mind.

Physician: I know your heads probably feeling a little fuzzy right now.

Patient: Just a little.

Physician: You think you can give me a brief summary of what we're going to do?

Patient: No.

Physician: (laughs). Ok.

Patient: Problems 1 at a time, eliminate them, till you get to the root, to the root of the problem.

Physician: $O k$. 


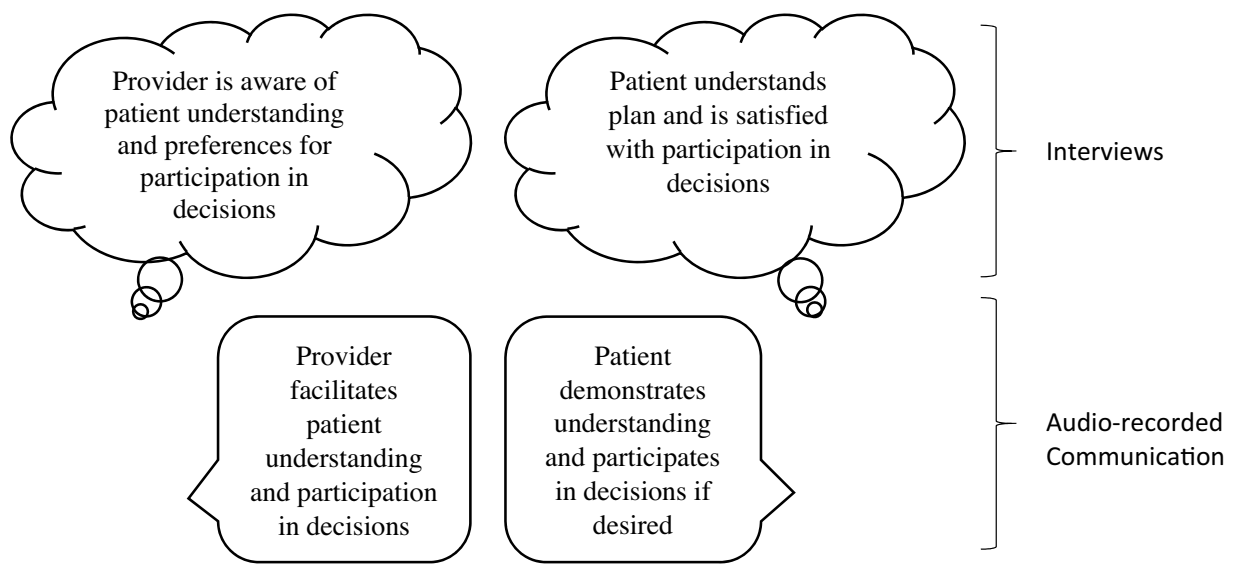

Fig. 1. Ideal patient-physician inpatient interactions.

Patient: At least that's the way I'd do it.

Physician: Are you comfortable not knowing the specifics at this point? Or would you like me to go over it again?

Patient: No they probably told me and I can't remember any of it anyway.

Physician: Ok. I can also write it down if you want.

2.2.1.2. Physician communication behaviors that undermine patient understanding. The two primary communication behaviors displayed by physicians that appeared to undermine patient understanding were (1) giving too little information and (2) missing cues to patient misunderstandings. In Table 3, we provide an example of a physician telling the patient that she needs a major surgical procedure without explaining the risks and benefits, what the patient might expect to happen, or when and how the surgeon would explain the procedure in more detail.

There were several instances where physicians missed specific cues from the patient indicating misunderstanding. In one instance, the patient and her mother become concerned about bleeding when they misunderstand the difference between subcutaneous heparin and non-steroidal anti-inflammatory (NSAID) medications. The physician tries to reassure them that everything is fine but does not directly address the nature of the misunderstanding (see Table 3). Below, the patient asks a question that indicates she has the impression her gallbladder is part of her gastrointestinal tract but the physician doesn't seem to realize the nature of the misunderstanding, telling the patient that she's not correct without clarifying the location of the gallbladder.

Patient: So when you say your gall bladder removed, everything you eat it pass through you real fast?

Physician: No, no, no, it's not like that.

Patient: That's not true?

Physician: The gall bladder makes your food to get digested better, so that's the function of the gall bladder. You have pain here? No?

2.2.1.3. Physician awareness of patient understanding. Another significant issue affecting physicians' ability to facilitate patient understanding was simply lack of realization that the patient did not understand. When interviewed, the majority of physicians thought that their patient understood their condition and plan for treatment, but many patients could not describe what was going on. Examples are shown in Table 5. In contrast, nearly all physicians who indicated in post-encounter that they were aware of patient misunderstanding had explicitly assessed it during the encounter.

RA: And what did he do to make you think he didn't really understand, did he just keep asking questions or... ?
Physician: He didn't have that many questions, but when I had him try to tell me whether this was, you know, he had some chips and packages of food and we were going over the labels, and I tried to ask him questions about what, you know, how much sodium was in there and how many of these servings he could have, and he couldn't answer those questions.

Because it is essential for a physician to know what a patient understands, we include that knowledge (or lack of it) as an additional factor that facilitates or undermines patient understanding in Table 2 .

\subsubsection{Patient factors related to their own understanding}

2.2.2.1. Patient communication behaviors that facilitate their own understanding. Examples of patient communication behaviors that facilitate or indicate their own understanding are also found in Table 3. These are (1) asking questions, (2) repeating the plan, (3) asking for clarification from the physician, and (4) demonstrating knowledge. A fifth contextual factor was identified in the patient interviews: patient desire to be informed. Some patients expressed a great deal of motivation to be informed about their condition and treatment options, as in the following example:

RA: So where do you get your information, about procedures and things like that?

Patient: A lot of it, I do a little bit of Internet research, and then I talk to the doctor about what I should actually believe because you know the Internet's not 100\%. You know, talking to my doctor, you know, talking to other people that have chronic pancreatitis . . . . l like as much information as possible. Because I feel like when you don't know enough stuff it's a lot scarier, when you do you understand how to battle it and the tools you need to get through.

2.2.2.2. Patient communication behaviors that undermine understanding. Most patient factors that indicated lack of understanding of the treatment plan were shown by the absence of the communication behaviors that made their limited knowledge clear to their physician. For example, there were patients who didn't ask many questions or appear to know very much about what was happening to them. Occasionally, when interviewed, the patient was aware of this. One patient said, "I think sometimes I don't get questions, I have questions that I don't get necessarily answered all the time but then it's because when I go to see him I don't ask them, then I think about it later. So I think it's more of my own part, not giving my questions out there that I should have thought about." 
Table 3

Examples of physician and patient communication behaviors that facilitate or undermine patient understanding.

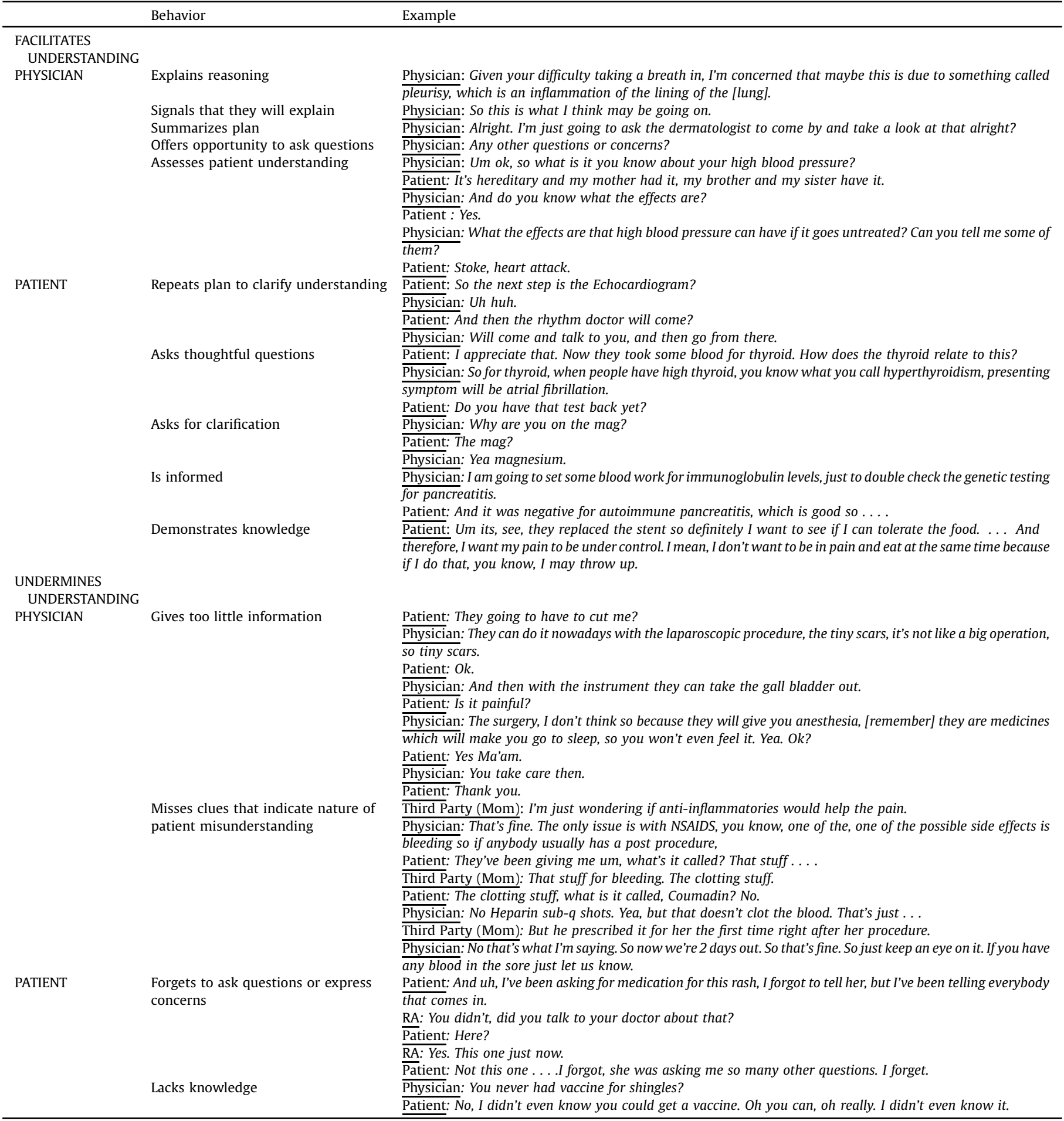

\subsection{Patient involvement in decisions}

\subsubsection{Physician behaviors related to patient involvement in decisions}

2.3.1.1. Physician behaviors that facilitate patient involvement. Examples of patient and physician communication behaviors that facilitate patient involvement in decisions are found in Table 4. Physicians sometimes, although rarely, asked the patient whether they had an opinion about what the plan might be. In all those cases, the decision had been made previously by the doctors, then plan was presented to the patient, and only then the patient was asked if that was okay or if there was anything else they expected. There were no examples of any decisions that were made with the patient.

2.3.1.2. Physician behaviors that undermine patient involvement. There were two physician behaviors that directly undermined patient involvement in decisions: being directive and 
Table 4

Examples of physician and patient communication behaviors that facilitate or undermine patient involvement.

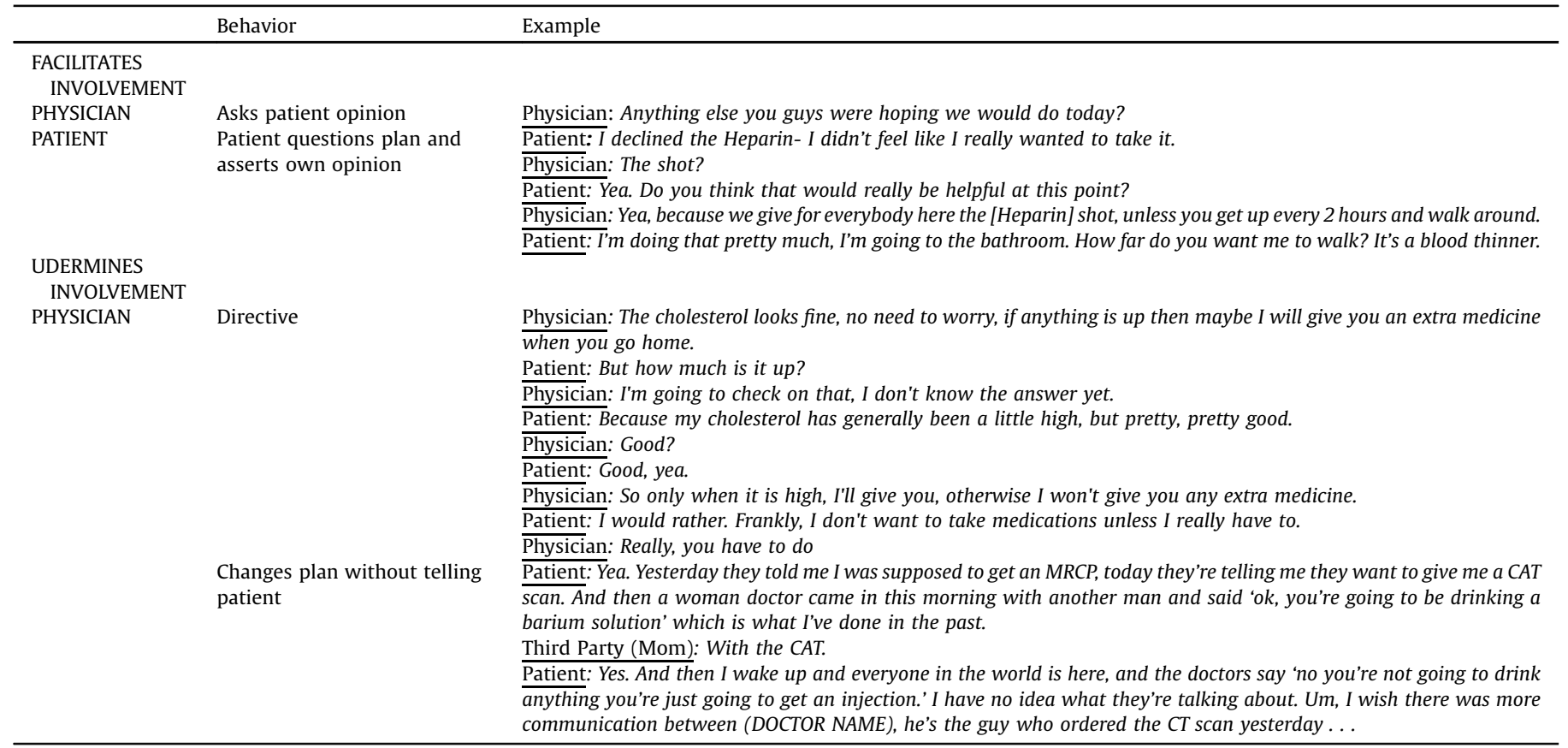

Table 5

Examples of physician overestimation of patient understanding.

\begin{tabular}{|c|c|c|c|}
\hline Example & Patient Interview & Physician Interview & Dialogue \\
\hline 1 & $\begin{array}{l}\text { RA: And can you describe what's going on during this } \\
\text { hospital stay to improve your health? } \\
\text { Patient: To improve my health. What's going on? Yea, the } \\
\text { doctors are coming in to see me, um, there running um, the } \\
\text { proper tests that they need to run? Can't quite describe all the } \\
\text { tests because they use terminology. }\end{array}$ & $\begin{array}{l}\text { RA: And do you think this patient understands this plan? } \\
\text { Physician: Yes. I do. } \\
\text { RA: What makes you think he understands it? } \\
\text { Physician: Uh, besides that he appeared to comprehend } \\
\text { what the next steps of the plan are going to be, and that he } \\
\text { asked good questions about it }\end{array}$ & $\begin{array}{l}\text { Patient: Nice meeting you. You covered } \\
\text { quite a bit there. It's a lot to take in } \\
\text { (laughs). } \\
\text { Physician: It is. } \\
\text { Patient: And remember. }\end{array}$ \\
\hline 2 & $\begin{array}{l}\text { RA: Can you describe what the doctor thinks needs to be done } \\
\text { before the doctor thinks you're ready to go home, if you've } \\
\text { talked about it yet? } \\
\text { Patient: They're going to find out what it is and they're going } \\
\text { to go in and operate I think, I'm not sure. }\end{array}$ & $\begin{array}{l}\text { RA: And do you think she understands this? } \\
\text { Physician: Yea I do. } \\
\text { RA: Is there anything she did to make you think she } \\
\text { understands? } \\
\text { Physician: Maybe that I got feedback from her when I was } \\
\text { explaining her what is my impression, what is the plan. } \\
\text { Seems like she showed me understanding. }\end{array}$ & (No discussion of surgery) \\
\hline 3 & $\begin{array}{l}\text { RA: And do you know what they doctors plan in for you from } \\
\text { here on out? } \\
\text { Patient: No. I haven't seen the doctor yet today. } \\
\text { RA: The woman that just came in. } \\
\text { Patient: Yea. Well I seen her. Yea. } \\
\text { RA: Yea. } \\
\text { Patient: Yea. But she didn't say, she just said she would see } \\
\text { me you know, tomorrow or whatever. She didn't say how } \\
\text { long I'd be here. }\end{array}$ & $\begin{array}{l}\text { RA: And do you think she understands everything that's } \\
\text { going to happen? } \\
\text { Physician: Yes, I think she understands because she } \\
\text { reciprocated appropriately. } \\
\text { RA: Ok. What do you mean she did appropriately? } \\
\text { Physician: Yea because when I explained to her she seems } \\
\text { like, nodded her head and she said ok. Overall, her body } \\
\text { language suggests she's understanding what I'm saying. }\end{array}$ & $\begin{array}{l}\text { Physician: Ok, so seems like you have a } \\
\text { few things going on. You have shingles } \\
\text { that is caused by a virus. } \\
\text { Patient: Right. } \\
\text { Physician: So we have to treat that } \\
\text { infection, we have to give you } \\
\text { medication that kills that virus. } \\
\text { Patient: Right. } \\
\text { Physician: And give you meds for pain. } \\
\text { We want you to feel, be not having } \\
\text { much pain. } \\
\text { Patient: Right. } \\
\text { Physician: And another thing is your } \\
\text { COPD got worse. So we're treating you } \\
\text { with the medication, also antibiotic. } \\
\text { Patient: Oh I see. Ok. } \\
\text { Physician: Ok. } \\
\text { Patient: Alright. } \\
\text { Physician: You have any questions, any } \\
\text { concerns. } \\
\text { Patient: No, not right now. No. }\end{array}$ \\
\hline
\end{tabular}

changing the plan without notifying patients. Both behaviors were often associated with conflict when patients were trying to exert their own opinion and authority (examples found in Table 4).
There were many examples of physicians who were directive, even when the patient expressed reluctance, concerns or clear disagreement. One contentious situation arises when the patient 
tries to question and then protest, but the physician insists (see example Table 4). In another situation, the physician tells the patient. "You need a surgery. The surgeons have seen you in the emergency room, they said they're going to do the surgery as an outpatient. So, outpatient means maybe in 4 weeks from now. You have to see them in the clinic, they will give you a date, and then they operate. So you need to 2 types of procedures, one is today - endoscopy - and then you need definite procedure is a surgery for you. Ok?" This patient essentially agrees, but then when asked by the RA whether she got enough information, says "I guess they gave me the best that they could give me" and when asked if she was involved in decisions as much as she wanted, said, "I don't know. I'm a peacemaker."

\subsubsection{Patient behaviors related to their own involvement}

2.3.2.1. Patient behaviors that facilitate their own involvement. Far more often than having the doctor ask for the patient opinion, the patient asserted their opinion without being prompted (see Table 4 for example). In one situation, the patient was given a food tray that she refused. When the doctor asked her why she didn't eat it, she said, "I don't want to eat, I don't feel like eating. I want to have my pain under control first, and then I wanna come and eat because last time I kind of vomited." We then interviewed this patient to ask her understanding of the plan for discharge, she expresses her own plan:

RA: And can you describe what needs to be done before the doctor thinks you're ready to go home?

Patient: I think I need to be comfortable with the idea of going home. Like right now I'm still in a lot of pain, you know, not eating anything so I definitely think I need to be eating something like even if it's just saltines.

When the doctor was asked whether this same patient understood the plan, he said, "Um, she basically kind of told me the plan, that's how I know she understands. Because when I walked in ... she said 'I'm feeling better, the pain is better, I had clear liquid, I'm ready to go home when you're ready to send me home' so she basically presented the plan to me before I even went into the plan."

When interviewed, another patient told us, "I think the more involved you are the more chances you have of battling your condition or whatever, so I really like having a lot of involvement, you know, nobody knows your body better than you do, I feel like, how it reacts, not the anatomy or whatever.“

2.3.2.2. Patient behaviors that undermine their own involvement. Two general patient characteristics undermined their involvement in making decisions about treatment plans: lack of interest in engaging, and being too angry to engage. Several patients reported a distinct preference not to engage in treatment decisions, as in the following interview:

RA: Do you think you have a say, do you think um ...

Patient: I'm going to do what the doctor ordered, I never have before, but times change.

RA: Are you ok with that, would you like to participate more?

Patient: No. I'm not a doctor.

In one circumstance, the patient was too upset to engage. RA: And what's the doctor's plan for you while you're here?

Patient: [Knock] the hell out of me. Dope me up with all these pills. RA: And do you feel like you have enough information about what's going on while you're here?

Patient: Nope. Nope.

RA: What else would you like to know?

Patient: I don't know. I'm stressed out for real. Really at my edge right now ... . I just want, I just want to get this removed. I just want to know what to do. How long must I take this medicine before they take these thyroids out my neck? And then I just don't understand, why you going to take them out if I just got to take a pill for the rest of my fucking life.

\section{Discussion and conclusion}

\subsection{Discussion}

We found that patient understanding and engagement in hospital care were facilitated, or undermined, by a broad range of specific behaviors of patients and physicians. These findings extend a body of literature on patient autonomy and patientphysician communication to the hospital setting. By describing the productive ways in which physicians foster autonomy by facilitating patient understanding and participation in decisionmaking, as well as the pitfalls that undermine patient engagement, we provide a roadmap for improving communication, which we outline below.

Previous work has demonstrated that patients are challenged with receipt of a great deal of information in the hospital. Weber found that the exchange of medical information was the main topic of physician talk on ward rounds, with patients receiving 20 bits of medical/therapeutic information per contact during ward rounds [17]. This sheer quantity of information might be a barrier to understanding. Despite physicians' explanations to patients, many patients still don't understand everything, and patients don't understand as much as their doctor thinks they do [5-7]. The information is, in addition, not presented in clear language, but in medical jargon, which can increase the burden on patients and further alienate them. One study suggests that one simple physical behavior might facilitate understanding: patients of providers who sat vs. stood at bedside felt the provider spent more time, were more satisfied and reported better understanding of their condition [10].

Several other possible approaches to improving patient understanding are suggested by our findings. First, physicians should be aware that many patients do not understand fully their plan of care, and that patients may not express when they do not understand. Our interviews uncovered a great deal of misunderstanding even after physicians explained what was going to happen. The only instances in our study of a physician being aware of patient misunderstanding occurred when that physician directly assessed it by asking the patient. This 'teach-back' method has been associated in previous studies with knowledge retention among patients [18]. Therefore, physicians might adopt a lower threshold for assessing patient understanding, because requesting that the patient repeat back the plan may be the only way to ensure that patients have a good sense of what will happen to them while hospitalized. Further, physicians could be attentive to subtle signs that the patient does not understand, such as asking questions that uncover some confusion about pathophysiology, diagnosis or treatment, or not asking many questions at all.

In addition, rather than depending on the physician alone to educate the patient, team-based care can facilitate understanding, using aids like whiteboards, discharge coordination, bedside videos, open notes, and tablets (or other devices) for patient use [19]. One of the limitations of our study was that we focused solely on physician behaviors with patients, and we are well aware that much, if not most, of the communication regarding daily plan and activities with the patient is done by nurses. Other members of the treatment team (though not relevant to our particular setting) include trainees; further, support staff play important roles, though underexamined, in communication with the patient. Nevertheless, our study demonstrates why the whole team is so important - that patients are not getting sufficient information from their physicians during morning rounds. Nurses and other members of the healthcare team play vital roles, and yet we believe 
that physicians are motivated to and can still improve their communication for everyone's benefit. Another important aspect of team-based care is maintaining effective, clear, and consistent communication across handoffs (particularly relevant in a hospital setting, where most patients are initially seen in the emergency department), transitions of care (on admission and discharge), and continuity of care with primary care providers and on discharge [9]. While we did not directly investigate handoffs and coordination of care, those factors undoubtedly contributed to the setting and context in which the noted behaviors took place. Initiatives to facilitate patients' participation in decision making should be applied consistently across these domains, and be coordinated with these interprofessional transfers across settings of care.

Our study found that there were no shared decisions made during the course of the observed encounters. Physicians occasionally, although rarely, asked the patient's opinion about the plan of care after the decision had been presented to the patient. When patients expressed their opinion to physicians who were being directive, this nearly always resulted in conflict. Our study suggests that at least some hospitalized patients are more interested in participating in decisions; therefore, physicians should be prepared to engage in a collaborative process. More patient-centered communication practices might ameliorate such conflicts.

Other patients, however, did not express a desire for shared decision-making. Several reasons likely underlie these preferences in the hospital, including the increased vulnerability of patients in the inpatient setting which tends to heighten barriers and reinforce hierarchy between patient and physician [1]. For example, hospital inpatients are usually in bed, often not eating or walking normally, and may be medicated and fatigued. Further, 9 of the patients studied had been previously hospitalized; patients previously hospitalized for the same condition might be more predisposed to shared decision making through their familiarity with their medical condition, or less predisposed to shared decision making with the clinician, either because they analogize from previous visits or are not given the opportunity to reconsider the treatment plan pursued on past visits. Lastly, the patients in this study were hospitalized for relatively brief periods of time, on average between 1 and 2 days. Brief hospitalizations might pose a challenge for patient-physician communication both due to decreased opportunity for interaction and the limited time available for processing detailed medical information. It might also be the case that, since only one patient-physician dialogue was recorded per day, a previous, first dialogue, in which agendasetting took place, might have been missed in some patients. However, we think it unlikely that the research assistant missed such substantive conversations.

\subsection{Conclusion}

This study emphasizes the need to understand that behaviors on the part of both patients and providers can facilitate or limit the exercise of patients' autonomy in the hospital. This finding can support physicians and healthcare teams as they work to improve communication with inpatients.

\subsection{Practice implications}

Our findings that hospital inpatients often do not understand their plan of care directly after speaking with their physician, and that conflict sometimes occurs in the setting of directive communication, suggests that improving communication between physicians and hospitalized patients can foster patient autonomy and improve patient experience of care. If it is assumed (either explicitly or implicitly) on the part of the hospitalist or the care team in general that hospitalized patients want physicians to make recommendations and treatment decisions, this assumption should be reviewed with the patient, as early as possible in the course of their hospital stay.

\section{Acknowledgements}

This research was supported by a grant to Dr. Berger from The Greenwall Foundation as part of the Kornfeld Program in Bioethics and Patient Care. In addition, Dr. Beach was supported by K24 DA037804 from the National Institute on Drug Abuse and Dr. Boss was supported by K08HS022932 from the Agency for Healthcare Research and Quality.

\section{References}

[1] T.L. Beauchamp, J.F. Childress, Principles of Biomedical Ethics, Oxford University Press, USA, 2001.

[2] G. Elwyn, D. Frosch, R. Thomson, N. Joseph-Williams, A. Lloyd, P. Kinnersley, E. Cording, D. Tomson, C. Dodd, S. Rollnick, A. Edwards, Shared decision making: a model for clinical practice, J. Gen. Intern. Med. 1 (October (27)) (2012) 1361-1367.

[3] E.F. Boss, N. Mehta, N. Nagarajan, A. Links, J.R. Benke, Z. Berger, A. Espinel, J. Meier, E.A. Lipstein, Shared decision making and choice for elective surgical care: a systematic review, Otolaryngol. Head Neck Surg. 154 (March) (2016) 405-420.

[4] E.H. Ofstad, J.C. Frich, E. Schei, R.M. Frankel, P. Gulbrandsen, Temporal characteristics of decisions in hospital encounters: a threshold for shared decision making? A qualitative study, Patient Educ. Couns. 97 (November) (2014) 216-222.

[5] Z. Berger, A. Dembitzer, M.C. Beach, Reason for hospital admission: a pilot study comparing patient statements with chart reports, Narrat Inq Bioeth 3 (Spring) (2013) 67-79.

[6] D.P. Olson, D.M. Windish, Communication discrepancies between physicians and hospitalized patients, Arch. Intern. Med. 9 (August (170)) (2010) 1302-1307.

[7] D.R. Calkins, R.B. Davis, P. Reiley, R.S. Phillips, K.L. Pineo, T.L. Delbanco, L.I. Iezzoni, Patient-physician communication at hospital discharge and patients' understanding of the postdischarge treatment plan, Arch. Intern. Med. 12 (May (157)) (1997) 1026-1030.

[8] D.H. Newman, B. Ackerman, M.L. Kraushar, M.H. Lederhandler, A. Masri A. Starikov, D.T. Tsao, H.P. Meyers, K.H. Shah, Quantifying patient-physician communication and perceptions of risk during admissions for possible acute coronary syndromes, Ann. Emerg. Med. 66 (July) (2015) 13-18 (18. e1).

[9] J.M. Farnan, J.K. Johnson, V. Arora, Effective communication in the inpatient care setting: an essential competency for hospitalists, Hosp. Physician 42 (2006) 55-62.

[10] K.J. Swayden, K.K. Anderson, L.M. Connelly, J.S. Moran, J.K. McMahon, P.M. Arnold, Effect of sitting vs. standing on perception of provider time at bedside: a pilot study, Patient Educ. Couns. 86 (February (2)) (2012) 166-171.

[11] T.A. Mjaaland, A. Finset, B.F. Jensen, P. Gulbrandsen, Physicians' responses to patients' expressions of negative emotions in hospital consultations: a videobased observational study, Patient Educ. Couns. 84 (September (3)) (2011) 332-337.

[12] H. Weber, M. Stöckli, M. Nübling, W.A. Langewitz, Communication during ward rounds in internal medicine: an analysis of patient-nurse-physician interactions using RIAS, Patient Educ. Couns. 67 (August (3)) (2007) 343-348.

[13] E.H. Ofstad, J.C. Frich, E. Schei, R.M. Frankel, P. Gulbrandsen, Tempora characteristics of decisions in hospital encounters: a threshold for shared decision making? A qualitative study, Patient Educ. Couns. 97 (November (2)) (2014) 216-222.

[14] D.R. Calkins, R.B. Davis, P. Reiley, R.S. Phillips, K.L. Pineo, T.L. Delbanco, L.I. Iezzoni, Patient-physician communication at hospital discharge and patients' understanding of the postdischarge treatment plan, Arch. Intern. Med. 157 (May (9)) (1997) 1026-1030.

[15] J. Chen, T. McCormick, Annals of emergency medicine journal club. Am I having a heart attack, doc? Patient-physician communication for possible acute coronary syndromes, Ann. Emerg. Med. 66 (July (1)) (2015) 87-88.

[16] P. Salmon, N. Mendick, B. Young, Integrative qualitative communication analysis of consultation and patient and practitioner perspectives: towards a theory of authentic caring in clinical relationships, Patient Educ. Couns. 82 (March) (2011) 448-454.

[17] (a) H. Weber, M. Stöckli, M. Nübling, W.A. Langewitz, Communication during ward rounds in internal medicine. An analysis of patient-nurse-physician interactions using RIAS, Patient Educ. Couns. 67 (August (1)) (2007) 343-348; (b) M. White, R. Garbez, M. Carroll, E. Brinker, J. Howie-Esquivel, Is teach-back associated with knowledge retention and hospital readmission in hospitalized heart failure patients? J. Cardiovasc. Nurs. 1 (March (28)) (2013) 137-146.

[18] V.S. Bhamidipati, D.J. Elliott, E.M. Justice, E. Belleh, S.S. Sonnad, E.J. Robinson, Structure and outcomes of interdisciplinary rounds in hospitalized medicine 
patients: a systematic review and suggested taxonomy, J. Hosp. Med. Mar. 1 (2016).

[19] E.A. Laird, T. McCance, B. McCormack, B. Gribben, Patients' experiences of inhospital care when nursing staff were engaged in a practice development programme to promote person-centredness: a narrative analysis study, Int. J. Nurs. Stud. 30 (September (52)) (2015) 1454-1462.

Please cite this article in press as: Z.D. Berger, et al., Communication behaviors and patient autonomy in hospital care: A qualitative study, Patient Educ Couns (2017), http://dx.doi.org/10.1016/j.pec.2017.03.006 